\title{
Representações sociais sobre a saúde na velhice: um diagnóstico psicossocial na Rede Básica de saúde
}

\author{
Maria Cristina Triguero Veloz Teixeira \\ Clélia Maria Nascimento Schulze \\ Brigido Vizeu Camargo \\ Universidade Federal de Santa Catarina
}

\begin{abstract}
Resumo
O estudo tratou da temática da representação social da saúde na velhice. Participaram do estudo quatro grupos de sujeitos: um grupo de idosos doentes, um grupo de idosos saudáveis; um grupo de trabalhadores de um Centro de Saúde da rede municipal do Sistema Único de Saúde de Florianópolis e um grupo de pessoas que cuidavam de idosos no Hospital Universitário da Universidade Federal de Santa Catarina. Os dados foram coletados através da técnica de entrevista e a análise dos mesmos foi realizada com a ajuda de um software de análise quantitativa de dados textuais denominado Alceste. Os resultados mostraram que, ao que parece, os locais pesquisados ainda não conseguiram implementar todos os programas necessários para resolver os problemas de saúde da população idosa que atende. A teoria das representações sociais mostrou ser uma ferramenta muito importante para explorar necessidades de saúde sentidas pelos idosos participantes da pesquisa.
\end{abstract}

Palavras-chaves: Representações sociais, Saúde, Velhice.

\begin{abstract}
Social representation of health in the old age: A psychosocial diagnoses in the Basic Network of Health. The present study was concerned with the social representations of health in the old age. Four groups participated in the study: a group of unhealthy elderly people; a group of healthy elderly people; a group of municipal network health center workers from Florianópolis; and a group of care-takers who helped elderly relatives or friends hospitalized in the University Hospital in Florianópolis. Subjects were interviewed and the contents of their speech production were analyzed through the software Alceste. Results suggest subject's dissatisfaction with policies designed to attend the elderly population with health problems. They also indicated that the social representations theoretical approach was useful to diagnose the needs of elderly group interview.
\end{abstract}

Key words: Social representations, Health, Old age.

$\mathrm{O}$ $\mathrm{s}$ assuntos saúde na velhice e o idoso saudável, entre outros, têm suscitado diversas pesquisas nas $\mathrm{Ci}$ ências da Saúde, algumas das quais foram executadas em parceria com a Psicologia. Também este estudo contribui tanto para as Ciências da Saúde quanto para a Psicologia. O principal referencial teórico do trabalho foi a Teoria das Representações Sociais pressupondo que: a exploração das representações sociais poderia permitir o contato com imagens e conteúdos que expressassem, de certa forma, as necessidades de saúde sentidas pelas pessoas. No caso, as pessoas alvos deste estudo foram idosos.

As representações sociais constituem formas de conhecimentos socialmente elaborados que são produzidas pelos grupos de indivíduos para poder comunicar-se e entender tudo aquilo que lhe é estranho e não familiar. Nem todo as- sunto se torna um objeto de representação social para os grupos e, nem todos os fenômenos do mundo que rodeiam o indivíduo são tributários de converterem-se em problemas de pesquisa científica da representação social. Moscovici (1981) define a representação social da seguinte forma:

\footnotetext{
Por representação social nós queremos dizer um conjunto de conceitos, afirmações e explicações originadas no decurso do cotidiano, no decurso das comunicações interindividuais. Elas são equivalentes em nossa sociedade, aos mitos e sistemas de crenças das sociedades tradicionais; elas podem até mesmo ser vistas como uma versão contemporânea de senso comum (p.181).
}

O conceito de representação social permite explicar o lugar que ocupa a representação nas sociedades pensantes. 
Moscovici (1981) faz uma distinção entre os universos de conhecimentos consensuais e os universos de conhecimentos reificados. O primeiro universo é constituído a partir de nossas experiências e informações que recebemos e transmitimos através das tradições, da educação e da comunicação social entre os grupos. Aqui, cada indivíduo é um pensador amador e um emissor de opiniões e de pontos de vista na base das conversações diárias e todos têm os mesmos direitos de criar e de transmitir representações sociais. No universo reificado, a sociedade é vista como um sistema de diferentes papeis e classes, cujos membros são desiguais, pois que atingirão o lugar desejado em correspondência com sua competência profissional (Moscovici, 1981).

No caso do objeto de estudo que ocupou este trabalho (o idoso saudável), salientamos que não é a primeira vez que o mesmo faz parte da pesquisa em representação social, seja, como diz Sá (1998), pelo caráter extremamente ameaçador que a saúde e a doença têm para o indivíduo, ou pela atualidade que a temática apresenta não só para os que constroem teorias científicas, mas também para as pessoas leigas. Essas pessoas, que preferimos chamar de atores sociais, acabam construindo teorias de senso comum que, de uma parte servem para explicar esses fenômenos que estão sendo representados e, de outra, podem sustentar suas práticas sociais em relação a como permanecer saudável na velhice.

Alguns dos fatores que determinaram a execução desta pesquisa são:

- Observamos que no Sistema Único de Saúde de Florianópolis, a maior parte das políticas de saúde e do planejamento de programas de saúde é feita na base de necessidades normatizadas que, conforme o Modelo Taxionômico de Necessidades de Saúde de Bradshaw, (1977) são aquelas necessidades que definem os especialistas em relação a uma determinada norma desejável ou ótima (refletindo o estado do conhecimento e dos valores daqueles especialistas que as determinam). São necessidades estabelecidas unicamente a partir dos universos reificados.

- Outro fator diz respeito a que, em Janeiro de 1994 o Congresso Nacional decretou a lei 8.842 referente à Política Nacional do Idoso (Diário Oficial, 1994). Na seção 2, artigo 4, ela contém uma diretriz que exige a capacitação e a reciclagem em geriatria e gerontologia dos recursos humanos que prestam serviços aos idosos, mas nos Centros de Saúde de Florianópolis, o atendimento a pessoas idosas é realizado basicamente por especialistas em Clínica Geral.

Esses dois fatores contribuíram com a formulação do seguinte pressuposto: se no Centro de Saúde pesquisado, as necessidades de saúde dos idosos estão sendo avaliadas somente a partir de critérios normatizados, por quê não explorá-las, também, a partir dos próprios idosos?

Deve-se considerar, embora não sejam na perspectiva da noção de representação social, que em Florianópolis já existem trabalhos que exploraram alguns elementos em relação ao significado da saúde na velhice e do idoso (Elsen, Santos \& Gonçalves, 1988/1989; Gonçalves, Santos \& Silva, 1992). $\mathrm{Na}$ perspectiva propriamente dita da representação social, nós temos desenvolvido outros trabalhos sobre os assuntos velhice-envelhecimento-idoso (Guimarães, 1997, 1998; Veloz, Nascimento-Schulze \& Camargo, 1999).

Um planejamento de programas de saúde que pretenda satisfazer as necessidades de saúde de sua população precisa compreender os problemas de saúde advindos da própria comunidade. Assim considerado, compartilha-se a noção de necessidade de saúde proposta por Pineault e Daveluy (1989) de que as mesmas não devem ser reduzidas, simplesmente, a carências nos serviços de saúde, ou que podem ser determinadas somente por especialistas. A necessidade sentida de saúde é aquilo que faz falta para que a situação problemática ou o estado de saúde atual se transforme na situação desejada ou no estado de saúde ideal, em termos de meta futura. A determinação da necessidade de saúde, à qual Pineault e Daveluy (1989, p. 46) fazem referência, deve ser feita em conjunto, ou seja, entre quem padece o problema e quem deve resolver o problema. San Martin e Pastor (1988) assinalam que o eixo essencial a ser obtido por qualquer programa de saúde encontra-se no ponto de convergência entre as necessidades, a demanda e a oferta de serviços. No ano 1992, pesquisadores da Organização Panamericana da Saúde (OPS) se reuniram para refletir sobre algumas questões da chamada crise da saúde detectando que uma das características da crise era a ignorância da saúde pública no que diz respeito às concepções e às práticas da população em relação ao assunto saúde-doença. Não se nega a importância dos métodos normativos para o planejamento de programas de saúde, mas existem outras formas de fazê-lo. Trata-se aqui daqueles métodos participativos, um dos quais o presente estudo utilizou.

A problemática deste trabalho focou-se nos seguintes questionamentos:

- como pessoas idosas, cuidadores de idosos e os próprios trabalhadores da saúde representam o assunto idoso saudável?

- existirão atritos e conflitos nesses modos de representar esse tema?

O principal objetivo deste estudo foi delimitar os conteúdos e as informações das representações sociais sobre o idoso saudável que têm idosos, cuidadores de pessoas idosas e trabalhadores da saúde. Salienta-se que este estudo somente apresenta uma parte da pesquisa que foi realizada com a amostra já que, conforme algumas das exigências teóricas dos trabalhos de representação social (articular conteúdos e estrutura da representação), o relatório contido neste trabalho somente discute o relacionado com os conteúdos e informações da representação social do assunto idoso saudável. A análise da estrutura desse mesmo objeto também foi executada embora não se apresente aqui. Além disso, a pesquisa explorou o conteúdo e a estrutura de outro objeto da representação social: o idoso doente.

\section{Método e Participantes}

Conforme a natureza do objeto de estudo deste trabalho (a representação social do idoso saudável), a seleção e a subdivisão dos grupos da amostra seguiram critérios de tipo taxionômico e os participantes distribuíram-se em quatro gru- 
pos (2 grupos de idosos, 1 grupo de trabalhadores da saúde e 1 grupo de cuidadores de pessoas idosas).

O primeiro grupo era composto de 40 idosos que procuravam os serviços da Policlínica II do Bairro de Estreito (Florianópolis), solicitando atendimento por se sentirem doentes. Do total, 8 eram homens e 32 eram mulheres; suas idades oscilaram entre 60 e 81 anos (média de 67 anos). A Renda Familiar oscilava entre um e dois salários mínimos. As doenças de maior frequiência no grupo foram: Diabetes (15 pessoas), Hipertensão Arterial (10 pessoas) e Artrite (8 pessoas). Muitos desses idosos apresentavam mais de uma das doenças anteriores (pluripatologia característica da velhice).

O segundo grupo era composto de 40 idosos que eram atendidos na mesma Policlínica, não por se sentirem doentes, e sim para receber orientações sobre cuidados preventivos de saúde através de grupos operativos de ensino e de aprendizagem voltados para a promoção de saúde (cuidados da Diabetes, cuidados nutricionais na velhice, exercícios físicos e outros). Do total, 36 eram mulheres e 4 eram homens; as idades oscilaram entre os 60 e 83 anos (média de 70 anos); 15 pessoas recebiam entre um e dois salários mínimos e 25 recebiam entre quatro e seis salários ou mais de seis salários. A maior parte das doenças que apresentavam eram Diabetes, Hipertensão Arterial e Doenças Cardiovasculares. Da mesma forma que o grupo anterior, possuíam pluripatologia.

O terceiro grupo era formado por 40 trabalhadores desse Centro de Saúde da rede municipal do SUS de Florianópolis (Policlínica II do Bairro de Estreito). Dentre eles havia médicos, psicólogos, enfermeiros e auxiliares de enfermagem, assistentes sociais, técnicos de enfermagem e outros. Este grupo apresentou uma média de idade de 47 anos. Deles, 15 eram mulheres e 25 homens. A maior parte dos entrevistados tinha se formado há mais de 20 anos ou entre 11 e 20 anos. Vinte pessoas trabalhavam na Rede Pública de Saúde entre 11 e 20 anos e 17 o faziam há mais de 20 anos. Os médicos alternavam o atendimento público com o privado.

O quarto grupo era composto de 20 cuidadores de idosos hospitalizados na Clínica Médica do Hospital Universitário da Universidade Federal de Santa Catarina, Florianópolis, ou acompanhavam idosos doentes atendidos nos ambulatórios do mesmo hospital. A média de idade foi 48 anos. Haviam 16 mulheres e 4 homens. A maior parte deles eram casados e tinha nível de escolaridade primário ou secundário. Os parentescos predominantes com o idoso foram os de filho/a (9) e os de esposo/a (5). Deste grupo, 9 pessoas eram os cuidadores únicos e 11 revezavam o cuidado com outras pessoas.

$\mathrm{Na}$ coleta dos dados, usou-se uma técnica de entrevista que tinha uma pergunta básica: no seu entendimento, como você vê ou percebe um idoso saudável? As entrevistas permitiram explorar os conteúdos e as informações relativas as representações sociais deste tema.

A análise dos dados foi feita com a ajuda do software Alceste - Análise Lexical Contextual de um Conjunto de Segmentos de Texto (Reinert, 1990). Por isso, após a transcrição das 140 entrevistas, foram constituídos três "corpus de análise" (conjuntos de respostas a questão da entrevista), um para cada tipo de participante (os dois primeiros grupos foram tratados em conjunto).

Em linhas gerais, este programa informático divide cada corpus em segmentos de texto (unidades de contexto elementar ou "u.c.e"), em seguida procede a uma análise hierárquica descendente (cruzando o vocabulário com os segmentos de texto de forma a obter classes de u.c.e. que compartilhem seus vocabulários, ao mesmo tempo em que se diferenciem dos outros conjuntos de u.c.e.). A análise hierárquica descendente oferece ao pesquisador classes léxico-semânticas compostas de conjuntos de palavras associadas significativamente a determinada classe (usa-se a prova do quiquadrado de associação), bem como a de conjuntos de segmentos de texto típicos de cada classe (nos quais podemos recuperar o ambiente de significação de cada palavra). Estas classes podem indicar, quando houver, associações com as características dos autores do material textual, já que o programa reconhece as unidades de contexto inicial (u.c.i.), no caso desta pesquisa cada entrevista, e as suas características (variáveis associadas). Maiores detalhes sobre este programa podem ser encontrados no seu manual (Image, 1988).

\section{Análise e discussão dos resultados das entrevistas com os grupos de idosos}

Este corpus continha 80 u.c.i. ou entrevistas $(40$ correspondiam ao grupo de idosos doentes e as 40 restantes ao grupo de idosos saudáveis). O software Alceste dividiu o corpus em 187 u.c.e., que continham 925 palavras, formas ou vocábulos diferentes. Após a redução dos vocábulos às suas raízes, obtiveram-se 120 palavras analisáveis (indicadores de sentido) que ocorreram 1981 vezes, o que significa uma média de ocorrência igual a 6 vezes. A análise hierárquica descendente reteve $56,15 \%$ do total de u.c.e do corpus (105 das 187 u.c.e) organizadas em três classes (Figura 1).

Observa-se o título de cada uma das classes, seguido pelo número de u.c.e que a compõe, pela descrição da classe e pelas palavras de maior associação com a mesma em função do coeficiente de associação $\chi^{2}$. Conforme o dendograma, houve uma primeira repartição do corpus em dois sub-corpus, um deles resultando a classe 2. Numa segunda repartição foram criadas as classes 1 e 3 .

\section{$O$ idoso saudável em função de fatores psicológicos}

A classe 1 envolveu a maior parte das u.c.e. deste corpus (75 u.c.e ou $71,43 \%$ das u.c.e. classificadas). A análise de suas variáveis descritivas permitiu caracterizá-la como uma classe produzida, fundamentalmente, pelos idosos doentes, com faixa etária de 66 a 70 anos, casados, com mais de quatro (4) filhos e morando com o cônjuge.

A maior parte dos conteúdos dessa classe agrupou-se ao redor de elementos psíquicos ou subjetivos indicados pelas palavras "cabeça", "doente", "idade", "viver", entre outras. Representou-se a condição de estar saudável na velhice como dependente do próprio indivíduo. Como diria Demócrito, essas pessoas entrevistadas vêem o homem como autor de sua 


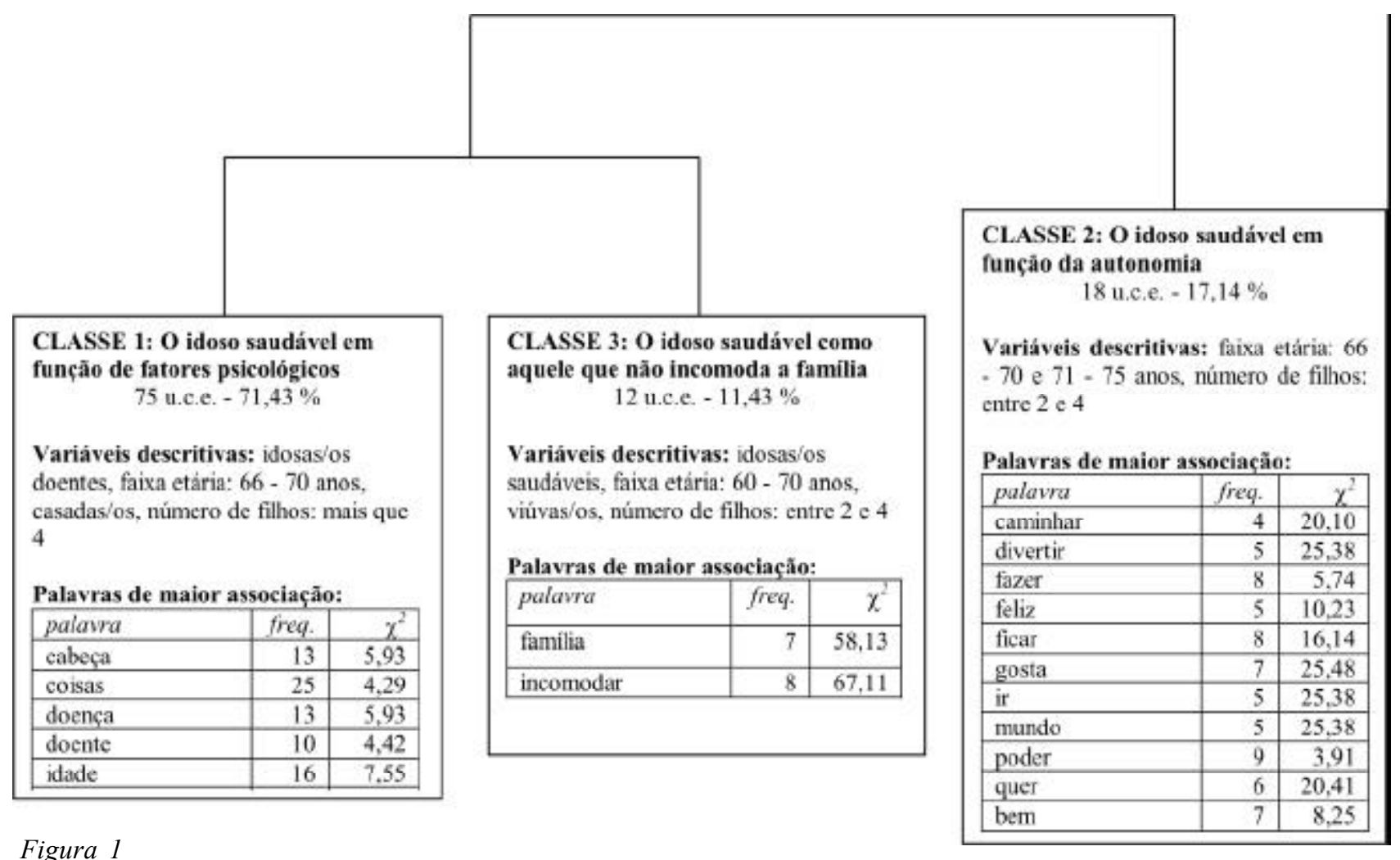

Figura 1

Dendograma de classes sobre a representação de um idoso saudável - grupo de idosos (n=80). Florianópolis, 1999.

própria saúde e, não, aquele homem que fica esperando que a saúde venha dos outros. Vejamos uma u.c.e da classe:

O idoso saudável para mim [...] Eu acho que tudo está na cabeça da gente. Há idosos que não têm nada e estão doentes, porque eu acho que é um problema da cabeça das pessoas, é um problema psicológico e muitas vezes eles ficam doentes para chamar a atenção porque estão com falta de carinho (Entrevistada 40 grupo de idosos doentes, 61 anos, casada, mora com o esposo).

Esta resposta indica que nesse grupo pensa-se que a condição primordial para se estar saudável na velhice é a estabilidade psíquica. Como essa classe foi típica de idosos que, no momento da coleta de dados, estavam doentes, inferimos que aqui existe uma representação social da velhice saudável que se traduz em expectativa diante das necessidades de saúde deles próprios. Os conteúdos representacionais podem estar expressando problemas de saúde que precisam ser resolvidos. Parece que uma necessidade de saúde dessas pessoas é estar em equilíbrio psíquico consigo mesmo, independentemente das doenças que elas possam ter. É como se a possibilidade de cura decorresse do equilíbrio emocional. Dados semelhantes já foram encontrados em outra pesquisa sobre a representação social da saúde (Gonçalves, 1994; Nascimento-Schulze, Garcia \& Arruda, 1995).

Os elementos desta classe nos levam a uma outra reflexão: se essa crença de que o equilíbrio emocional traz saúde regulasse o comportamento desses sujeitos, acredita-se que isto seria uma forma de auto-intervenção em saúde que eles poderiam executar em benefício deles mesmos.
Outras u.c.e encontradas nessa classe apontaram para outros conteúdos relacionados com aspectos emocionais só que, desta vez, com o bem-estar, com a alegria e com a felicidade. Por exemplo:

O idoso saudável para mim é aquela pessoa que sempre está contente, sem importar nem a própria doença. É a alegria de viver [...] Quando ele tem aquele contentamento e quando tem alegria de viver, quando ele sabe controlar não ter dores, não ter doenças e ter uma boa cabeça para estar sempre alegre (Entrevistado 23 - grupo de idosos doentes, 63 anos, casado, mora com a esposa).

De alguma maneira, os idosos, principalmente os do grupo de pessoas doentes, compartilharam uma representação social de saúde na velhice baseada na noção de bem-estar emocional. Isso mostra que, pelo menos em termos do conhecimento compartilhado por estes idosos, a ausência de doença física não constitui o único indicador de saúde na velhice.

\section{$O$ idoso saudável em função da autonomia}

Conforme demonstra o número de u.c.e que compõe esta classe 2 (18 u.c.e - 17,14\%), em comparação com a anterior (classe 1), ela é uma classe menos compartilhada pelo grupo de idosos entrevistado. O conteúdo desta classe não apresentou-se associado ao tipo de idoso (seja este um idoso saudável ou doente). Contribuíram mais para ela idosos com um número menor de filhos do que os que contribuíram para a classe anterior (de 2 a 4). Esta classe inclui também a contribuição de pessoas mais velhas (66-75 anos). 
Pelas suas u.c.e e pelas palavras típicas da classe (caminhar, divertir, fazer, poder), os conteúdos apontaram para uma representação do idoso saudável em função da autonomia. Os verbos de ação ocupam um papel central nas respostas dadas ao que significa idoso saudável.

Embora ainda existam dificuldades para se chegar a um consenso operativo de como definir a autonomia na velhice, concordamos com o critério da OMS (1984), quando afirma que um dos melhores indicadores de autonomia de um idoso é o grau em que este consegue desenvolver-se na sociedade como deseja. No trabalho, as únicas pessoas que citaram esse tipo de conteúdo representacional para definir um idoso saudável pertencem ao sexo feminino. É como se, para as mulheres, as imagens que melhor explicam o assunto idoso saudável fossem a independência e a capacidade para manter seu lar, viajar, passear etc.

É a coisa mais maravilhosa do mundo, é uma pessoa que tem muita saúde, que pode viajar bastante, que faz tudo o que ele quer. Um idoso saudável gosta de se arrumar, de ir para tudo o que é canto e se divertir, que não fica dentro de casa [...] (Entrevistada 19 - grupo de idosos doentes, 73 anos, viúva, mora sozinha).

Essa u.c.e pertence a uma idosa doente. É provável que alguns dos problemas de saúde que ela tinha estivesse interferindo na sua autonomia. Isto nos leva a pensar que a representação social do envelhecimento sadio, por parte dos idosos, pode ser um instrumento útil para detectar necessidades de saúde, pois que a teoria do senso comum que eles compartilham envolve suas aspirações.

Um último aspecto que pode ser discutido nesta classe diz respeito à relação que existe entre representações sociais e as práticas sociais. O conteúdo desta classe indica como se conduzir no dia a dia para ser uma pessoa idosa saudável, ou seja caminhar, ir a lugares, divertir-se para ser feliz.

A classe 3 (ver Figura 1) tem pequena importância. Basicamente ela traz a preocupação do idoso solitário em não incomodar a família (sobretudo os filhos), então este fato aparece como o principal indicador do que seria saudável na velhice.

\section{Análise e discussão dos resultados das entrevistas com o grupo de trabalhadores da saúde}

Nesse grupo de sujeitos, o Alceste processou 40 u.c.i ou entrevistas que formaram o corpus da análise. Esse corpus foi dividido em 101 u.c.e, que continham 767 palavras diferentes. Com a redução dos vocábulos às suas raízes, obtiveramse 93 palavras analisáveis que ocorreram 1009 vezes, ou seja, média de 4 vezes. A análise hierárquica descendente considerou 80 das 101 u.c.e (79,21\% do total de u.c.e do corpus).

Conforme mostra a Figura 2, na primeira repartição das u.c.e do corpus obtiveram-se dois sub-corpus (o segundo originou a Classe 4). Numa segunda repartição, o primeiro sub-corpus (lado esquerdo) originou dois outros sub-corpus (um deles originando a classe 2. Uma terceira repartição resultou nas classes 1 e 3 . Analisaremos aqui as classes com maior número de u.c.e. (as classes 2 e 4), que juntas respondem por $73,75 \%$ do total de u.c.e.

\section{$O$ idoso saudável como função da prática de atividades}

A classe 2 tem 26 u.c.e (32,50\% do total). A variável profissão não está associada a esta classe. Ao se falar de risco em saúde, considerou-se um fato que potencialmente pudesse produzir dano à saúde de um indivíduo. No caso de pessoas idosas, um dos fatores de risco, que pode provocar problemas de saúde, é a inatividade (Baltes, 1994; Fernández-

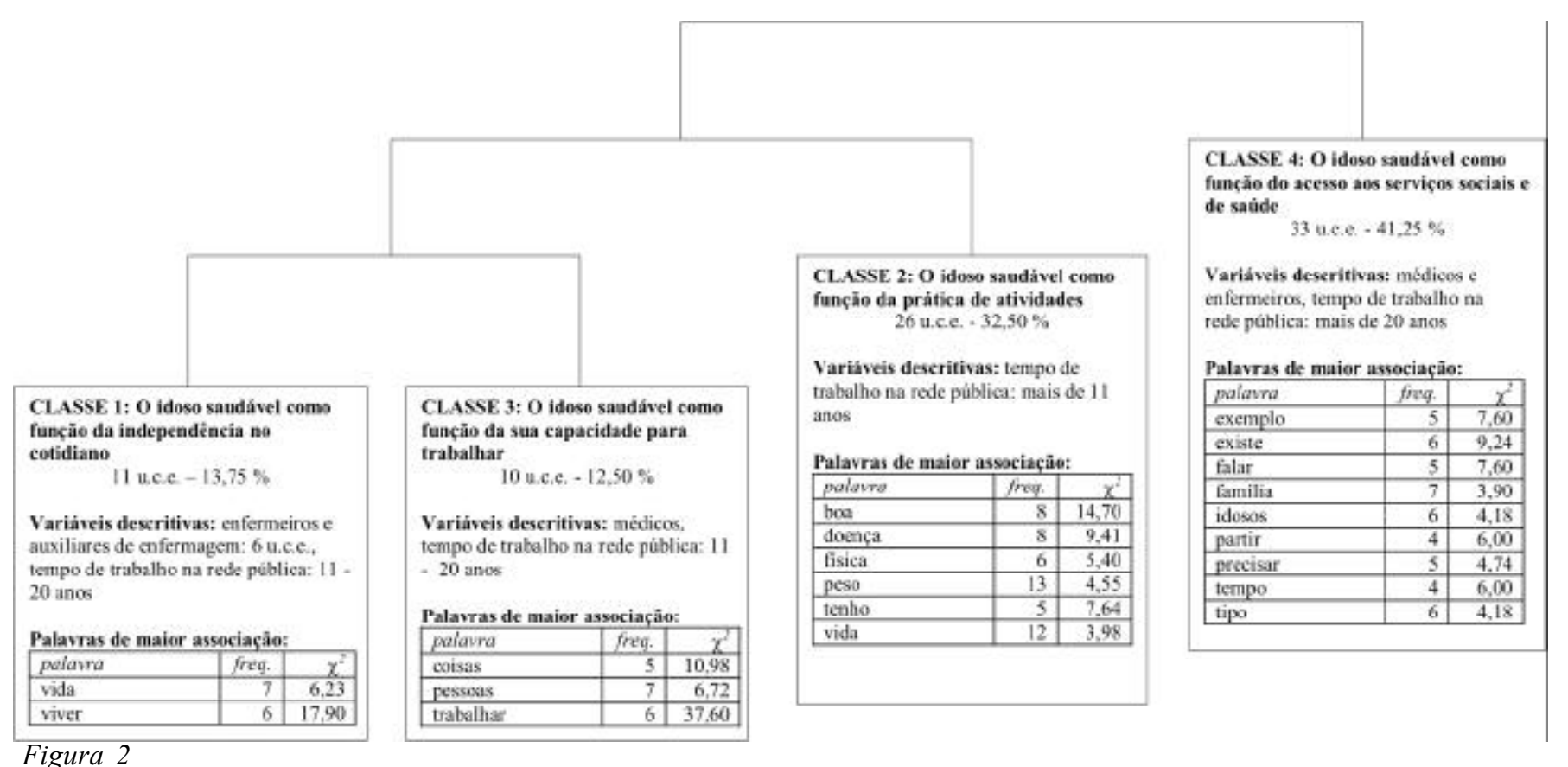

Figura 2

Dendograma de classes sobre a representação de um idoso saudável - grupo de trabalhadores de saúde (n=40). Florianópolis, 1999. 
Ballesteros et al., 1992; Kane \& Kane, 1993). Contrariamente, o comportamento da prática de atividades ou de exercícios físicos serve para prevenir doenças e, obviamente, não só em pessoas idosas. Aliás, quanto mais cedo essa prática se estabelece para o indivíduo, tanto maior o benefício para a sua saúde. A prática de atividades é uma imagem do idoso saudável que prevalece tanto no universo de conhecimentos do senso comum (entre as pessoas leigas) quanto no universo reificado (ou de especialistas). De certa forma, o exercício físico é um assunto científico para vários saberes da ciência, assim como também o é para temas de conversa do dia a dia de pessoas não especialistas. Vejamos, a seguir, uma das u.c.e.:

Que tenha uma vida ativa em todos os sentidos, saúde para mim é atividade (Entrevistado 10 - médico, 44 anos, 14 anos de trabalho na Rede Pública).

O sentido da representação predominante nesta classe consistiu em estabelecer uma relação de dependência do estado de saúde da prática de atividades. No entanto, houve alguns elementos representacionais de u.c.e que afirmavam que o idoso saudável é aquele que não tinha doenças. $\mathrm{O}$ exemplo seguinte ilustra este tipo de concepção:

Para mim, saudável é a ausência de doenças, isso seria hoje um idoso que não tem doenças (Entrevistado 18 - médico, 50 anos, 18 anos de trabalho na Rede Pública).

Esse conteúdo ancora-se numa idéia bastante improvável de se constituir como fato, conforme comprovam diferentes achados epidemiológicos, aquela de se chegar aos 60 anos ou mais sem ter, pelo menos, alguma doença (Hood \& Dincher, 1995; Lachs \& Pillemer, 1995).

\section{O idoso saudável como função do acesso aos serviços sociais e de saúde}

A classe 4 abrange 33 u.c.e (41,25\% do total). Foi a classe que mais u.c.e apresentou. Contribuíram para esta classe as profissões de médico e enfermagem.

Os conteúdos da classe apontaram diferentes aspectos do atendimento social e de saúde ao idoso representados por algumas palavras como "família" e "precisar". Os exemplos de u.c.e., que serão apresentados, indicam que o conteúdo refere-se ao conhecimento especializado das ciências da saúde. Trata-se de uma categoria denominada "acesso à saúde" e compreende tanto a disponibilidade de recursos de atenção em determinado local e tempo, como as características desse recurso que facilitariam ou dificultariam o acesso ao serviço (Frenck, 1985). O primeiro exemplo de u.c.e a ser citado mostra as características do "recurso governo" que muitas vezes não disponibiliza a atenção ao idoso.

O que mais conta na saúde do idoso é o descaso do governo, isso é essencial, se o governo desse mais atenção, mais ou menos desde os quarenta anos, para se preparar para a velhice, então, se poderia falar de idosos saudáveis (Entrevistado - 5, auxiliar de enfermagem, 45 anos, 18 anos na rede pública).

A segunda u.c.e mostra como o recurso "rede pública de saúde" não permite o acesso da população a ele próprio.
Aqui por exemplo, na rede pública, não existem condições para atender ninguém. Então falar de saúde no idoso no Brasil é uma mentira. Há que mudar muito, muito mesmo. O intuito de saúde está por aí (Entrevistado 30 - médico, 48 anos, 20 anos na rede pública).

Essas u.c.e sugerem que a condição de saúde de uma pessoa idosa depende da qualidade do serviço de saúde que lhe é oferecida, seja um serviço curativo ou preventivo. A partir dos conteúdos produzidos por estes profissionais de saúde da rede do SUS, observa-se que prevalecem dificuldades nos dois aspectos assinalados por Frenck (1985) a respeito do conceito de acesso. Apesar deste conteúdo estar presente na representação social dos trabalhadores de saúde, um efeito mais benéfico desta forma de conhecimento compartilhado, para a saúde pública, estaria ligado a possibilidade da mesma influenciar a prática destes trabalhadores no sentido da mudança da situação verificada.

Um outro elemento de representação relacionado com o acesso aos serviços diz respeito a várias u.c.e que apontaram a situação financeira como condição necessária para garantir estar saudável na velhice. Só que desta vez, perante as dificuldades de acesso ao serviço público, os trabalhadores da saúde representaram o estar saudável na velhice como dependente da condição financeira que lhe possibilita o acesso ao serviço privado. Por exemplo:

Um idoso saudável é quem tem dinheiro, pelo menos aqui no Brasil. Eu nunca seria bem atendido se não tivesse dinheiro. Eu sou muito sincero, e caridade quase não existe hoje no Brasil (Entrevistado 30 - médico, 48 anos, 20 anos na rede pública).

As classes 1 e 3 têm pouca importância para este corpus analisado. Elas trazem as idéias de independência nas atividades cotidianas (compartilhada pelos enfermeiros) e da capacidade de trabalhar (compartilhada pelos médicos) associadas à noção de idoso saudável.

\section{Análise e discussão dos resultados das entrevistas com o grupo de cuidadores de pessoas idosas}

Nesse grupo, o corpus total para a análise de dados teve 20 u.c.i ou entrevistas. O corpus foi dividido em 45 u.c.e, que continham 389 palavras diferentes. Com a redução dos vocábulos às suas raízes, obteve-se 35 palavras analisáveis que ocorreram 375 vezes, uma média de 4 vezes cada uma. A análise hierárquica descendente reteve 42 das 45 u.c.e. $(93,33 \%$ do total).

Conforme a Figura 3, houve uma única repartição do corpus em duas classes. Do total de u.c.e. considerado pela análise hierárquica descendente, exatamente, a metade pertence a cada uma das duas classes $(50 \%)$.

\section{O idoso saudável como função do estilo de vida}

Os cuidadores que mais contribuíram para esta classe eram revezados e guardavam relações de parentesco mais distantes com o doente.

Assim como a maioria das u.c.e que tipificaram a classe, as palavras de maior associação com a mesma (feliz, poder, 


\begin{tabular}{|c|c|c|c|c|c|}
\hline \multicolumn{3}{|c|}{$\begin{array}{l}\text { CLASSE 1: O idoso saudável como } \\
\text { função do estilo de vida } \\
\qquad 21 \text { u.c.e. }-50,00 \%\end{array}$} & \multicolumn{3}{|c|}{$\begin{array}{l}\text { CLASSE 2: } O \text { idoso saudável como } \\
\text { função da autonomia } \\
\qquad 21 \text { u.c.e. }-50,00 \%\end{array}$} \\
\hline \multicolumn{3}{|c|}{$\begin{array}{l}\text { Variável descritiva: tipo de } \\
\text { parentesco variado }\end{array}$} & \multirow{2}{*}{\multicolumn{3}{|c|}{$\begin{array}{l}\text { Variável descritiva: tipo de } \\
\text { parentesco: esposo(a) ou filho(a) } \\
\text { Palavras de maior associação: }\end{array}$}} \\
\hline \multicolumn{3}{|c|}{ Palavras de maior associação: } & & & \\
\hline palavra & freq. & $x^{2}$ & palavra & freq. & $x^{2}$ \\
\hline doença & 7 & 5,56 & alegre & 5 & 5,68 \\
\hline feliz & 5 & 5,68 & cuidado & 9 & 8,40 \\
\hline poder & 7 & 5,56 & idade & 7 & 8,40 \\
\hline saudável & 17 & 3,86 & importar & 4 & 4,42 \\
\hline estar & 10 & 7,47 & pessoas & 14 & 7,78 \\
\hline ter & 6 & 4,29 & bem & 7 & 5,56 \\
\hline eu & 9 & 6,04 & sempre & 13 & 12,55 \\
\hline
\end{tabular}

Figura 3

Dendograma de classes sobre a representação de um idoso saudável- Grupo de cuidadores de idosos (n=20). Florianópolis, 1999.

saudável e estar) remetem a noções de promoção de saúde e de cuidados no estilo de comportamento ao longo do curso de vida. Vejamos um exemplo de u.c.e:

Eu acho que para poder estar saudável na velhice, as pessoas não podem maltratar tanto o corpo quando são jovens. Saúde é poder ter toda essa estrutura de jovem para poder segurar a velhice, que infelizmente só traz doença à gente (Entrevistado 1 - cuidador revezado, 48 anos, nora do idoso, primeiro grau).

Da mesma forma que é difícil falar de um estado ideal de saúde, é difícil, também, definir os estilos de vida que podem ser considerados como ótimos para todas as pessoas. Para considerar um estilo de vida como bom ou ruim, é necessário ter em consideração uma série de fatores, por exemplo: a cultura, a renda financeira, a vida social, a idade, as capacidades físicas, as tradições, o ambiente familiar e o próprio trabalho, entre outros. É muito interessante que parte dos cuidadores, que participaram do estudo, tenham manifestado esse consenso acerca do assunto idoso saudável. Relacionando o conteúdo desta classe com o estudo sobre representação social da saúde de Herzlich (1991), no qual se verificou uma associação harmoniosa da saúde à pessoa, como se isso fosse natural e não precisasse de explicação, podemos constatar o quanto é diferente o modo de pensar a saúde quando se trata de considerarmos as pessoas idosas. Nesse trabalho, quase trinta anos depois do estudo de Herzlich, um grupo de entrevistados não atribui naturalidade ao fato de estar saudável na velhice. Pelo contrário, as u.c.e citadas mostram que uma pessoa pode nascer com uma boa constituição, mas isso não determina que ela vai ser saudável na velhice. Estes cuidadores pensam que os estados de saúde na velhice são construídos pelas pessoas ao longo de todo o curso de vida.

\section{O idoso saudável como função da autonomia}

Na classe 2, os cuidadores caracterizavam-se, ao contrário dos que contribuíram mais para a classe 1 , por terem um grau de parentesco mais próximo do doente (esposo/a ou filho/a) e por existir um número maior de cuidadores únicos.

Apesar da multiplicidade de palavras associadas a classe (alegria, cuidado e idade, importar, pessoas etc.), a maior parte dos conteúdos das u.c.e concretizaram uma representação social do idoso saudável em função da autonomia que ele possa ter para realizar uma vida diária normal, independentemente de ter alguma doença crônica. Por exemplo:

\footnotetext{
É aquela pessoa que se alimenta bem, que cuida bem de seu coração e da pressão, que consegue, apesar da idade, caminhar sozinho, enfrentar a vida com coragem (Entrevistado 19 cuidador revezado, 30 anos, filho do idoso).
}

A falta de autonomia que o idoso possa ter é um importante fator que faz com que o cuidador sinta-se esgotado. Ao teorizar sobre o idoso saudável é provável que os cuidadores reafirmem a autonomia, como característica central, pois representa uma boa expectativa para quem cuida de um idoso, um menor esforço na tarefa.

\section{Considerações finais}

Ao longo da análise dos dados, observou-se que existem alguns conteúdos presentes nas respostas de quase todos os sujeitos entrevistados, independente do grupo a que 
pertenciam. Citam-se aqui a autonomia e a execução de atividades de forma independente. É como se o fato de ser autônomo e independente tivesse um forte poder associativo e simbólico com o objeto da representação social que foi explorado: o idoso saudável. Esses conteúdos citados acima podem ser considerados como elementos estáveis da representação social estudada, o que mostra que, ao redor dos mesmos existiu um modo de pensar compartilhado e consensual entre os grupos. Estes conteúdos, embora façam parte de suas teorias de senso comum, apresentam elementos análogos aos conceitos da ciência gerontológica e geriátrica. Lembramos aqui, um aspecto apontado por Sá (1998), para alguns profissionais, às vezes, observamos uma atenuação da distinção teórica entre os universos consensuais e os universos reificados de conhecimentos (entre as teorias do leigo e aquelas do especialista).

Nos grupos de idosos e de trabalhadores da saúde, a ancoragem do assunto "idoso saudável", com base na sua autonomia, significa que não há dissensão entre eles, pelo menos no que diz respeito a forma de pensarem o assunto. Mas, e na prática social, há consenso ou divergência? Este trabalho não explorou nenhum aspecto que diz respeito à satisfação dos idosos com os serviços que eles recebem, porém ao finalizar a pesquisa foi elaborado um relatório minucioso do estudo e encaminhado à Policlínica para ser discutido. O objetivo deste relatório foi o de promover a discussão se a prática de necessidades normatizadas atingia ou não as necessidades sentidas de saúde dos idosos que eram atendidos e que foram entrevistados.

O estudo mostrou que as necessidades de saúde de um idoso não devem ser deduzidas somente a partir de pessoas doentes. Da mesma forma que foram encontrados conteúdos de representações da saúde compartilhados por todos, também foram encontrados conteúdos que evidenciaram diferenças entre os diversos grupos participantes da pesquisa. Para os idosos, os fatores mentais foram conteúdos muito valorizados para explicar o idoso saudável. Já para os trabalhadores, o acesso que esses idosos têm aos serviços de saúde, assim como a qualidade desses serviços foram os aspectos mais importantes. Para o grupo de cuidadores, o estilo de vida foi um dos aspectos mais valorizados. De certa forma, cada um desses conteúdos da representação social do idoso saudável apontou para a existência de necessidades de saúde do idoso.

Os resultados do estudo não podem ser generalizados a outros grupos, nem a outros Centros de Saúde. Contudo, acreditamos que uma das contribuições mais relevantes da pesquisa foi beneficiar os programas de atendimento ao idoso, que os trabalhadores de saúde da Policlínica II do Bairro de Estreito, Florianópolis, SC executam e, conseqüentemente, beneficiar ao próprio idoso; a esse sábio que, embora seja um amador ou leigo em matéria de ciência da saúde, também conhece como se manter saudável e quando está doente.

\section{Referências}

Baltes, P. B. (1994). Envelhecimento cognitivo: potencialidade e limites. Gerontologia, 2, 23-44.
Bradshaw, J. (1977). The concept of social need. In N. M. Gilbert \& H. Specht (Orgs.), Planning for social welfare: Issues, models and tasks (pp. 290296). New Jersey: Prentice Hall.

Diário Oficial da República Federativa do Brasil (1994, 5 de janeiro). Brasília: Imprensa Nacional. p. 15.

Elsen, I., Santos, L. L. C., \& Gonçalves, L. H. T. (1988/1989). Significado do Envelhecimento e da saúde para o idoso. Revista Ciências da Saúde, 7(8), 71-85.

Fernandez-Ballesteros, R., Izal, M., Montorio, I., González, J. L., \& Diaz, P. (1992). Evaluación e intervención psicológica en la vejez. Barcelona: Martínez Roca.

Frenck, J. (1985). El concepto de accesibilidad. Revista de Saúde Pública de Mexico, 27(5), 438-452.

Gonçalves, L. H. T., Santos, L. L. C., \& Silva, Y. F. (1992). Ser ou estar saudável na velhice. Revista Texto e Contexto em Enfermagem, 1(2), 76-88.

Gonçalves, V. L. B. (1994). A gente que tem o amarelão tem que se conformar. A atenção à saúde na perspectiva dos idosos. Dissertação de mestrado nãopublicada. Universidade de São Paulo, São Paulo.

Guimarães, M. C. T. V. (1997). Velhice: perda ou ganho? Dissertação de mestrado não-publicada. Universidade Federal de Santa Catarina, Florianópolis.

Guimarães, M. C. T. V. (1998). Velhice: perda ou ganho. Revista Arquivos de Geriatria e Gerontologia, 2(2), 52-59.

Herzlich, C. (1991). A problemática da representação social e sua utilidade no campo da doença. Physis. Revista de Saúde Coletiva, 1(2), 23-36.

Hood, H. G., \& Dincher, J. R. (Org.). (1995). Fundamentos e prática da Enfermagem. Atendimento completo ao paciente. Porto Alegre: Artes Médicas.

Image (1998). Alceste: Analyse de données textuelles. Toulouse: Manuel d'utilisateur.

Kane, R. A., \& Kane, R. L. (1993). Evaluación de las necesidades en los ancianos. Guia práctica sobre los instumentos de medición. Madrid: Fundación de la Caja de Madrid.

Lachs, M. S., \& Pillemer, K. (1995). Abuse and neglect of the elderly persons. The New England Journal of Medicine, 332(7), 437-443.

Moscovici, S. (1978). A representação social da Psicanálise. Rio de Janeiro: Zahar.

Moscovici, S. (1981). On social representations. In J. P. Forgas (Org.), Social cognitions perspectives on everyday understanding (pp. 181-209). New York: Academic Press.

Nascimento-Schulze, C. M., Garcia, A. I. F., \& Arruda, D. C. (1995). Health paradigms, social representations of health and illness and theirs central nucleus. Papers on Social Representations. Threads of discussion, 4(2), 187-198.

Organização Mundial de Saúde. (1984). Aplicaciones de la epidemiologia al estudio de los ancianos. Informe de un Grupo Científico de la OMS sobre la Epidemiología del Envejecimiento. In Organização Mundial de Saúde, Serie de Informes Técnicos 706. Genebra: Autor.

Organização Panamericana de Saúde - OPS. (1992). Sobre la teoria y la práctica de la salud pública: un debate, múltiples perspectivas. La crisis de la Salud Pública: reflexiones para el debate. Washington: Autor.

Pineault, R., \& Daveluy, C. (1989). La planificación sanitaria. Conceptos, métodos, estrategias. Barcelona: Masson.

Reinert, M. (1990). Alceste, une méthodologie d'analyse des données textuelles et une application: Aurélia de $\mathrm{G}$ de Nerval. Bulletin de méthologie sociologique, 28, 24-54.

Sá, C. P. (1998). A construção do objeto de pesquisa em representações sociais. Rio de Janeiro: EdUERJ.

San Martin, H., \& Pastor, V. (1988). Salud comunitaria. Teoria y práctica. Madrid: Díaz Santos.

Veloz, M. C. T., Nascimento-Schulze, C., \& Camargo, B. V. (1999). Representações sociais do envelhecimento. Psicologia: Reflexão e Crítica, 12(2), 479-501. 
Maria Cristina Triguero Veloz Teixeira, doutora em Filosofia da Saúde pela Universidade Federal de Santa Catarina, é Professora Assistente I da Universidade Presbiteriana Mackenzie).

Endereço para correspondência: Rua Jorge Americano, 141. Bairro Alto da Lapa. 05083-130, São Paulo, SP. E-mail cris@teixeira.org.

Clélia Maria Nascimento Schulze, doutora em Psicologia Social pela University of Bristol, Bristol, Inglaterra, é Professora titular do Departamento de Psicologia da Universidade Federal de Santa Catarina. Pesquisadora do CNPq. Membro do Laboratório de Psicossociologia da Comunicação e de Cognição Social - LACCOS).

Endereço para correspondência: Universidade Federal de Santa Catarina. Centro de Filosofia e Ciências Humanas, Campus Universitário Trindade. Caixa Postal 476, 88040-900, Florianópolis, SC. E-mail cleli@matrix.com.br.

Brigido Vizeu Camargo, doutor em Psicologia Social pela École des Hautes Études en Sciences Sociales de Paris, França, é Professor adjunto do Departamento de Psicologia da Universidade Federal de Santa Catarina. Supervisor do Laboratório de Psicossociologia da Comunicação e de Cognição Social - LACCOS.

Endereço para correspondência: Universidade Federal de Santa Catarina. Centro de Filosofia e Ciências Humanas, Campus Universitário Trindade. Caixa Postal 476, 88040-900, Florianópolis, SC. E-mail brigido@cfh.ufsc.br. 